inhalation technique is not fully addressed, despite the FDA recommendation that the technique should be trained using an Inspirease, a spacer device. The problem of a consistent inhaler technique when patients use MDIs has been extensively reported ${ }^{9-11}$ and hence could affect the reproducibility of any method related to lung deposition in asthmatics, despite extensive training of the technique. Furthermore, this variability of salbutamol deposition would be enhanced by the pathophysiology of a patient's respiratory tract. ${ }^{12}$ Variability of the bioassay will also be introduced by the training effect of the inhalation technique with respect to steroid therapy, hyperresponsiveness due to previous bronchoprovocation, and the length of salbutamol washout periods. Furthermore, the protocol is very demanding on the asthmatic subjects and our projection is that the drop out rate will be high which, together with the strict inclusion criteria, may introduce bias. Nevertheless, to answer the criticism in the two letters, we are planning clinical studies to compare our urinary excretion method with a bronchoprovocation test and the influence of inhaler technique will be studied first.

In vivo deposition studies using a radiolabel ${ }^{13}$ have indicated that the bronchodilator response seems to depend on the total amount delivered to the lungs. ${ }^{14-16} \mathrm{~A}$ recently reported abstract, using labelled salbutamol aerosols, has shown differences in regional lung deposition related to the technique and, when total lung deposition was high, there was a corresponding increase in the amount delivered to the different regions of the lungs. ${ }^{17}$ This is why we will evaluate the influence of inhaler technique in our bronchoprovocation studies. An ongoing study in our laboratories is showing a linear relationship between one, two, three, four, and five ( $n=12$ subjects) inhaled salbutamol doses from an MDI and the amount renally excreted. This suggests that an increase in dose delivered to the lungs produces a simultaneous increase in the renal elimination of salbutamol.

Finally, Drs Watson and Lewis state that a significant number of patients claim that they find generic salbutamol inhalers to be less effective than the original branded products. This information should be reported to the regulatory authorities. All inhaled products contain patient information leaflets describing the inhaler technique which should be used, and examination of these reveals different instructions. It may be the confusion created by these differences which causes patients to complain. If the pharmaceutical industry cannot agree on the standardisation of the information on how to use an MDI, then perhaps the British Thoracic Society should provide these guidelines. Any argument that different techniques are recommended because of the MDI formulations, characteristics, etc is not substantiated in the literature. J K CHEGE
H CHRYSTYN The School of Pharmacy,
University of Bradford, Bradford BD7 IDP,

$U K$

1 Hindle $M$, Chrystyn $H$. Determination of the relative bioavailability of salbutamol in the lung following inhalation. Br f Clin Pharmacol 1992; 34:311-5.

2 Janson C. Plasma levels and effects of salbutamol after inhaled or ${ }^{3} \mathrm{H}$ iv administration in stable asthma. Eur Respir $\mathcal{F}$ 1991;4:544-50.
3 Chege JK, Chrystyn H. Volumatic usage: some generic salbutamol metered dose inhalers can be used. Thorax 1994;49:1162-3.

4 Hindle $M$, Chrystyn $H$. Relative bioavailability of salbutamol to the lung following inhalation using metered dose inhalation methods and using metered dose inhalation methods

5 Hindle $M$, Newton DAG, Chrystyn H. Investigations of an optimal inhaler technique with the use of urinary salbutamol excretion as a measure of relative bioavailability to the lung. Thorax 1993;48:607-10.

6 Lipworth BJ, Clark RA, Dhillon DP, Moreland TD, Struthers AD, Clark GA, et al. Pharmacokinetics, efficacy and adverse effects of sublingual salbutamol in patients with asthma. Eur 7 Clin Pharmacol 1989;37:567-71.

7 Consensus Statement of the British Association for Lung Research. Determining equivalence of inhaled medications. Respir Med 1995 (in press)

8 Adams WP, Poochikian G, Taylor AS, Patel RM, Burke GP, Williams RL. Regulatory aspects of modifications to innovator bronchodilator metered dose inhalers and development of generic substitutes. F Aerosol Med 1994;7:119gen

9 Compton GK. Problem patients have using pressurised aerosol inhalers. Eur $\mathcal{F}$ Respir Dis 1982;63(Suppl 119):101-4.

10 Allen SC, Prior A. What determines whether an elderly patient can use a metered dose inhaler correctly? Br 7 Dis Chest 1980;80:45-9.

11 Engel T, Scharling B, Skovsted B, Heinig JH Effects, side effects and plasma concentrations of terbutaline in adult asthmatics after inhaling of terbutaline in adult asthmatics after inhaling inhalation flows and volumes. $\mathrm{Br} \mathcal{F}$ Clin Pharmacol 1992;33:439-44.

12 Vidgren $M$. Factors influencing lung deposition of inhaled aerosols. Eur Respir Rev 1994;4 68-70.

13 Newman SP. Delivery system. In: Barnes PJ, ed. New drugs for asthma. Volume 2. London: ed. New drugs for asthma. Volume 2. London: IBC

14 Hultiquist C, Wollmer P, Eklundh G, Jonson B. Effect of inhaled terbutaline sulphate in relation to its deposition in the lungs. Pulmon Pharmacol 1992;5:127-32.

15 Johnson MA, Newman SP, Bloom R, Talace N, Clarke SW. Delivery of albuterol and ipratropium bromide from two nebulizer systems in classic stable asthma. Efficacy and pulin classic stable asthma. Efficacy and

16 Zainudin BMZ, Biddiscombe M, Tolfree EJ, Sprio SG. Comparison on bronchodilator responses and deposition patterns of salbutamo inhaled from a pressurised metered dose inhaler, as a dry powder, and as a nebulised solution. Thorax 1990;45:469-73.

17 Farr SJ, Rowe AM, Rubsamen R, Taylor G. Optimisation of aerosol inhalation from metered dose inhalers by use of a novel microprocessor - controlled device. Pharm Res 1994; 11(Suppl):S-158.

\section{Diffuse pulmonary fibrosis and Hermansky-Pudlak syndrome}

Dr Reynolds and colleagues (June 1994;49: 617-8) report a case of interstitial fibrosis of the lung proven at necropsy in a patient with Hermansky-Pudlak syndrome (HPS). They mention that they had identified 18 more cases in the literature.

The exact number of patients with HPS and pulmonary fibrosis or restrictive lung disease is difficult to determine as several cases seem to have been published on more than one occasion without correct cross referencing. Based on our search of literature we estimate that approximately 50 patients with HPS and pulmonary fibrosis or restrictive lung disease have been observed (bibliographic data in two) including the two necroscopic cases we published. Women seem to be affected more often than men. Only very few reports exist on pulmonary fibrosis in siblings with HPS. ${ }^{1-3}$
Contradictory data exist regarding the identification of ceroid in lungs of HPS patients with pulmonary fibrosis. Pigmentladen macrophages were seen in some patients ${ }^{4}$ but not in others. ${ }^{5}$ In one case no ceroid was reported at open lung biopsy when fibrosis already existed, but was identified at necropsy. ${ }^{6}$

In the first of two brothers with HPS and interstitial fibrosis we observed numerous pigment-laden macrophages in the lungs at necropsy but none in the second, despite him having more severe pulmonary fibrosis. The deposition of ceroid cannot therefore be the only cause of pulmonary fibrosis in patients with HPS.

\section{WERNER WÖCKEI Department of Pathology Zentralkrankenhaus Gauting D 82131 Gauting/Munich, Germany \\ JOACHIM SÜLTZ \\ Von-Richthofen-Strasse 15 D 86356 Neusäss, Germany}

1 Wöckel W, Sültz J, Hübner G, Arnholdt H, Wernert $\mathrm{N}$, Häußinger $\mathrm{K}$, et al. HermanskyPudlak-Syndrom mit Lungenfibrose bei zwe Brüdern. Pathologe 1992;13:82-9.

2 Davies BH, Tuddenham EGD. Familial pulmonary fibrosis associated with oculocutaneous albinism and platelet function defect. A new syndrome. $Q 7$ Med New Series 1976;178:219-32.

3 Hoste P, Willems J, Devriendt J, Lamont H, van der Straeten M. Familial diffuse interstitial pulmonary fibrosis associated with oculocutaneous albinism. Report of two cases with a family study. Scand $₹$ Respir Dis 1979;60 128-34.

4 Garay SM, Gardella JE, Fazzini EP, Goldring RM. Hermansky-Pudlak syndrome. Pulmonary manifestations of a ceroid storage dismonary manifestations of a ceroid sto

5 DePinho RA, Kaplan KL. The HermanskyPudlak syndrome. Report of three cases and review of pathophysiology and management considerations. Medicine 1985;64:192-202.

6 Takahashi A, Yokoyama T. Hermansky-Pudlak syndrome with special reference to lysosomal dysfunction. A case report and review of the dysfunction. A case report and review of the
literature. Virchows Arch [A] 1984;402:247-58.

\section{Combined chemotherapy and radiotherapy in advanced pulmonary blastoma}

We were interested to read the recent case report of Dr Chin et al (August 1994;49: 838-9) describing a case of pulmonary blastoma in an adult presenting as a chronic loculated effusion.

We admitted a 57 year old man in 1991 with left shoulder pain, hoarseness, dyspnoea and Horner's syndrome. Chest radiography revealed a $11 \times 12 \mathrm{~cm}$ mass in the upper zone of the left hemithorax. At fibreoptic bronchoscopy the left vocal cord was paralysed and the left upper lobe bronchus obliterated with a necrotic lesion. Because of the localisation of the lesion, transthoracic lung biopsy was performed and histological examination revealed a pulmonary blastoma. A computed tomographic scan revealed mediastinal invasion by the mass. No distant metastases were detected. The patient was inoperable and conflicting results have been reported regarding the use of chemotherapy, radiotherapy alone, or in combination. ${ }^{1-3}$ We gave combined modality treatment using cisplatin, etoposide, and adriamycin as chemotherapy.

After two cycles of chemotherapy $6000 \mathrm{cGy}$ radiotherapy was given to the lesion and a $75 \%$ regression was noted in the tumour 
mass. After radiotherapy two further cycles of chemotherapy were given. Unfortunately the patient died of neutropenic sepsis in the 10 th month of treatment.

We believe that combined chemotherapy and radiotherapy can be used in this immunohistopathologically and clinically rare tumour.

SERAP HASTÜRK YURDANUR ERDOĞAN AYŞE ÖZYILDIRIM ECE ÇAKIR Atatürk Chest Diseases Hospital,
Ankara, Ankara,
Turkey

1 Koss MN, Hochholzer L, O'Leary T. Pulmonary blastoma. Cancer 1991;67:2368-81.

2 Karcioğ lu AZ, Someren AO. Pulmonary blastoma: a case report and review of the literature. Am f Clin Pathol 1974;61:287-95.

3 Manivel JC, Wood JR, Watterson J, et al. Pleuropulmonary blastoma. The so-called pulmonary blastoma of childhood. Cancer 1988;62:1516-26.

\section{BOOK NOTICE}

Epidemiology of Lung Cancer. J M Samet. (Pp 544; \$175.00). New York: Marcel Dekker, 1994. 0824788532.

Epidemiology of Lung Cancer is a comprehensive overview of this malignancy in terms of environmental causes, lifestyle factors, familial aggregations, individual susceptibility, and genetic determinants. These and other circumstances of exposure are covered in separate chapters, with each chapter standing on its own. The careful reader will achieve, in a time effective way, a nicely balanced, comprehensive update of what is known today about factors capable of increasing or decreasing the incidence of lung cancer in human populations.

The critical reviews and the summing up of evidence on each of the human exposures are based on empirical findings, mainly epidemiological studies in the form of population-based investigations or hospital-based multicentre studies of lung cancer conducted around the world during the last five decades. In most cases the results are studied in the light of evidence of carcinogenicity in experimental animals and other available information on genetic and related effects of the exposure. Exposures considered exhaustively are tobacco smoking (active and passive) which is by far the most important single risk factor for lung cancer, air pollution, radon, asbestos and manmade fibres, arsenics, silica, diet and - most importantly - interactions thereof, in particular with tobacco smoking. In addition, a full chapter is devoted to the documentation and discussion of the role of individual susceptibility for developing lung cancer.

Overall, the book is well written, clearly organised, and comprehensive in scope. The authors who have contributed to this work are well recognised in the field. In my opinion it is a very useful book for anyone who is involved in the treatment and care of patients with lung cancer. As written by Sir Richard Doll in the introduction chapter: "Epidemiology has already taught us enough for it to be possible to ensure that lung cancer ceases to be the most common form of fatal cancer throughout the world and that it returns to the place it occupied in the nineteenth century among the least common human cancers, if society is prepared to act on the knowledge obtained".- $\mathrm{JHO}$

\section{CORRECTION}

\section{New perspectives on inhaled drug delivery and systemic bioactivity}

In the editorial entitled "New perspectives on inhaled drug delivery and systemic bioactivity" by B J Lipworth, which appeared on pages $105-110$ of the February issue, figure 2 on page 106 was incorrectly labelled; $13 \mu \mathrm{g}$ in part A should have read $13 \%$ and $33 \mu \mathrm{g}$ in part B should have read $33 \%$. The figure is reproduced here with the labelling correctly applied.
NOTICES

4th European Congress of Extracorporeal Life Support

The 4th European Congress of Extracorporeal Life Support will be held in Bergamo, Italy on 10-12 May 1995. For further information please contact Mr Matteo Salvi, ECMO Conference, Centro Congressi Giovanni XXIII, Viale Papa Giovanni XXIII, 106, 24121 Bergamo, Italy. Telephone: +39 35 236435. Facsimile: +39 35236474 .

Clinical Applications of Pulmonary Function Testing

A course on "Clinical Applications of Pul- on monary Function Testing" organised by Pro- $\bigoplus$ fessors J M B Hughes and N B Pride will be held at the Hammersmith Hospital, 2 and 3 November 1995. The course will consist of $J$ lectures, demonstrations and case discussions on physiological background, methods and applications of usual and not so usual pulmonary function tests and will be of interest to $\overrightarrow{0}$ doctors and pulmonary function technicians. of For further information contact the Wolfson Conference Centre, Royal Postgraduate Medical School, Hammersmith Hospital, London W12 0NN. Telephone: +44181740 3117/3245. Facsimile: +441817404950.

A

Fluticasone Diskhaler $1000 \mu \mathrm{g}$

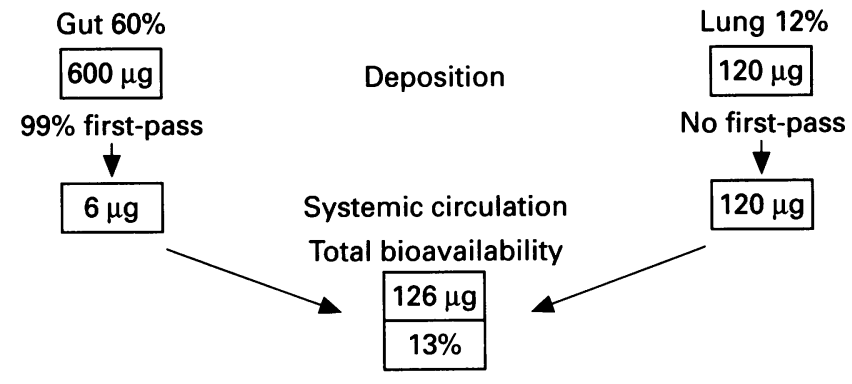

ung $12 \%$

B

Budesonide Turbohaler $1000 \mu \mathrm{g}$

Gut $56 \%$

Lung $27 \%$

$560 \mu \mathrm{g}$

Deposition

$270 \mu \mathrm{g}$

$89 \%$ first-pass

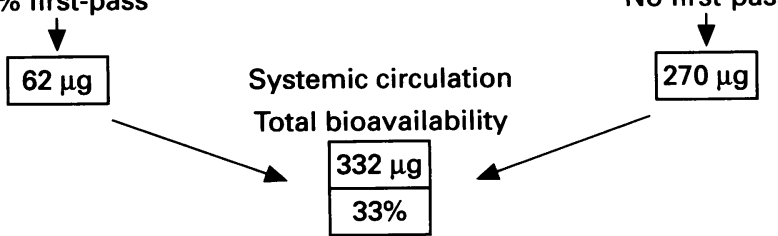

Figure 2 Schematic representation of systemic bioavailability of $(A)$ futicasone propionate and $(B)$ budesonide given by respective dry powder inhaler devices. 